\title{
ANALYSIS OF SPATIAL AND TEMPORAL VARIATIONS IN CROP WATER PRODUCTIVITY OF THE RAINFED WHEAT FOR A REGIONAL SCALE ANALYSIS
}

\author{
MOHAMMAD HADI NAZARIFAR, MOHAMMAD HASHEM KANANI*, \\ REZVANEH MOMENI
}

College of Abouraihan, University of Tehran, Tehran

NAZARIFAR, M.H. - KANANI, M.H. - MOMENI, R.: Analysis of spatial and temporal variations in crop water productivity of the rainfed wheat for a regional scale analysis. Agriculture (Pol'nohospodárstvo), vol. 58, 2012, no. 2, pp. 65-73.

\begin{abstract}
Water productivity is a suitable indicator in water potential analysis at a location. Hence in this study, changes in water use and productivity are studied in spatial and temporal scale simultaneously. Temporal changes in water productivity in Hamedan region (Iran), was determined with Standard Precipitation Index (SPI). To estimate regional water productivity, GIS and Kassam method were coupled to estimate the potential yield of rainfed wheat. Thus, layers of radiation and temperature were created using geo-statistical subprogram in GIS environment and subsequently, potential yield for the entire area were determined. To determine actual evapotranspiration, the region was discrete into homogeneous areas using Thieson method in Arcinfo software, and potential evapotranspiration of the crops were calculated by Cropwat software. Using the method recommended by FAO, these values were converted
\end{abstract}

to actual evapotranspiration. The map of spatial coverage of the water productivity was prepared for the whole region by overlapping the two layers: the potential yield and the actual evapotranspiration. Results of this study indicate that the combined analysis of spatial and temporal characteristics is advantageous. This can help in carrying an effective analysis and results in a broader knowledge of the indicators under consideration. Amount of water productivity in drought condition in comparison with the other two conditions was higher and from geographical point of view, the southern parts of the region have higher potential production when compared to other locations of the province. The analysis shows that the variation in amount of active radiation received by the earth surface is causing these differences.

Key words: standard precipitation index (SPI), drought, Kassam method, water productivity

The world's population has increased from 2.5 billion to more than 6 billion during the last 50 years (Billib et al. 2009). The population in Iran has increased with the same rate from 6 million in 1956 to about 65 million in the beginning of 2001 and it is expected, with the implementation of all population control programs, to reach to about 100 million in 2022 (Ehsani \& Khaledi 2003). Due to increasing population and consequently water consumption in current situation, the water requirement will increase to about 266 billion cubic metres in 2022 . Hence, the water resources will not be adequate to fulfil the required volume (Jahani 2001). In order to respond to increasing demand and achieve food security of the society a comprehensive study on agricultural planning is required to reach the maximum economic use in different climatic regions of Iran and promote water productivity from 0.7 to $2 \mathrm{~kg}$ per cubic metre of water (Nazarifar et al. 2007). Generally speaking, the term 'water productivity' refers to the magnitude of output or benefit resulting from the input quantum of water as applied on a unit base. In the domain of agriculture, it is expressed as the net consumptive use efficiency in terms of yield per unit depth of water consumed per unit area of cultivation (Kjine et al. 2003). Agricultural water productivity can be expressed either as a physical productivity in terms of

Mohammad Hadi Nazarifar, Research Assistant, Rezvaneh Momeni, Department of Irrigation and Drainage Engineering, College of Abouraihan, University of Tehran, Tehran, P.O.Box 11365-4117, Pakdasht, Iran

Mohammad Hashem Kanani, M.S. in Library \& Information Science, College of Abouraihan, University of Tehran, Iran. E-mail: mhkanani@ut.ac.ir (*Corresponding author) 
the yield over unit quantity of water consumed (tones per ha.cm of water or $\mathrm{kg}$ yield per $\mathrm{kg}$ water consumed) in accordance with the scale of reference that includes or excludes the losses of water or an economic productivity replacing the yield term by the gross or net present value of the crop yield for the same water consumption (rupees per unit volume of water) (Molden \& Sakthivadivel 1999).

One of the examples of research carried on efficiency of water use for various agricultural crops in regional scale is that of Heinemann et al. (2002) in Tybajy River Basin. They used GIS and plant models in combination. They showed that the crop growth simulation models linked to GIS can be an effective tool to help determine irrigation requirement and water productivity for river basin and large catchments. Amor et al. (2002) applied crop growth simulation models coupled with geographic information system to analyse water productivity in Laoag River Basin in the Philippine to study water productivity in spatial and temporal dimensions, for three crops (rice, corn and peanuts), in both existing and potential agricultural areas. The results showed that temporal and spatial analysis of water productivity could provide substantial information for water saving opportunities and, hence, strategies in irrigated agriculture. Oweis and Hachum (2003) carried out considerable research for improved water productivity of dry farming systems in West Asia and North Africa. The results showed that substantial and sustainable improvements in water productivity can only be achieved through integrated farm resources management. On-farm water-productive techniques if coupled with improved irrigation management options, better crop selection and appropriate cultural practices, improved genetic make-up, and timely socioeconomic interventions will help to achieve this objective. Conventional water management guidelines should be revised to ensure maximum water productivity instead of land productivity. Ahmad et al. (2004) carried diagnostic analysis of spatial and temporal variations in crop water productivity for a field scale analysis of the rice-wheat cropping system of Punjab, Pakistan. To sustain and/or enhance water productivity, the management of uncontrollable factors such as climatic variability along with the improvements in controllable factors such as agronomic and water management practices need careful planning and actions. The application of a comprehensive set of wa- ter balance and water productivity indicators for spatial and temporal analysis could help in performance evaluation of irrigated crops and devising strategies for improving food production and water productivity. Hussain et al. (2007) provided an overview of the issues in, and approaches to, measuring and enhancing the value of agricultural water in large irrigated river basins. They developed a framework and a set of indicators for valuing agricultural water by looking into various dimensions and underlying key factors that influence the value of water at micro, meso and macro levels. In addition, the research compiles recent estimates of the value of agricultural water, and outlines measures for enhancing the value of agricultural water. Singh et al. (2006) focused on the identification of appropriate strategies to improve water management and productivity in the Sirsa district, India. The field scale eco-hydrological model SWAP, in combination with field experiments, remote sensing and GIS, has been applied in a distributed manner generating the required hydrological and biophysical variables to evaluate alternative water management scenarios at different spatial and temporal scales. Improved crop husbandry in terms of improved crop varieties, timely sowing, better nutrient supply and more effective weed, pest and disease control, will increase crop yields and water productivity in this district. The scenario results further showed that reduction of seepage losses will improve significantly the long-term water productivity, halt the rising and declining groundwater levels, and decrease the salinisation in Sirsa district. Moayeri et al. (2011) assessed yield, water consumption and water productivity of maize at the Karkheh River Basin, Iran. The results and observations made during this study indicated that the most important reasons for low water productivity were inadequate knowledge of farmers in irrigation, plant nutrient deficiencies and improper crop management practices. Shah and Dalwadi (2011) done a study to demonstrate how remote sensing-based estimates of water consumption and water stress combined with secondary agricultural production data, which provide better estimates of irrigation performance, water productivity in north Gujarat, India based Dharoi Irrigation Scheme. The accuracy of measuring individual parameter from remote sensing data ranges between 80 and $90 \%$. Performance indicators are usually based on several parameters combined together, and the accuracy is therefore approximately 75 to $85 \%$. 
There are various methods to determine water productivity to estimate the actual yield which can identify the amount of actual yield for different regions. One of the most appropriate methods is Kassam method which has been improved by the International Institute of Reclamations (Kassam 1977) based on land and water relation. They have calibrated and tested the method using the measured data collected from field experiments. They have extracted a linear regression model to determine the dry biomass of crops: alfalfa, corn, sorghum and wheat and proposed mathematical relationships to convert the dry biomass into marketable product. But in the modified linear model while maintaining the previous assumptions another assumption for inclusion of maximum dry biomass in maximum evapotranspiration was introduced and by applying simple correction factors the marketable crop yield could be calculated.

The purpose of this research was to study the variations in water productivity in spatio-temporal scales. In order to analyse the temporal variation of water productivity Standard Precipitation Index (SPI) was used, and with the development of coupled GIS and combining Kassam method the spatial and temporal variations in water productivity was investigated in the region.

\section{MATERIAL AND METHODS}

Hamedan province is located between latitude $34^{\circ}$ and $35^{\circ} 46^{\prime} \mathrm{N}$ and between longitude $47^{\circ} 48^{\prime}$ and $49^{\circ} 28^{\prime} \mathrm{E}$. The region covers an area $19,493 \mathrm{~km}^{2}$ equivalent to 1.2 of per cent of the total area of the country (Iran). The climate is semi-arid and cold according to selyaninov classification (Zareabyaneh 2004), with an average annual precipitation of $330 \mathrm{~mm}$ and average annual temperature $12^{\circ} \mathrm{C}$ (www.irimo.ir).

The SPI was used for monitoring of drought, wet and normal conditions. In this study, 29 years (1973-2002) precipitation data of 13 stations has been used. These stations are monitored by two separate organizations: Meteorological department and the Regional Water Company in Hamedan province. The data of seven additional adjacent meteorological stations were used as complementary data for further analysis. Annual precipitation homogeneity was confirmed through Run test.
For the reconstruction and completing the sequence of data the SPSS software was used for correlating the stations through regression analysis (Yazdani \& Haghshenoo 2008).

SPI was calculated for 12 -month time scale. The results were analysed to explore the years related to three conditions: drought, wet and normal.

To estimate regional water productivity in the region, GIS and Kassam method were coupled to estimate the potential yield of rainfed wheat in a developed rasterised network with 30 resolutions in the region. This method, based on eco-physiological principles, is outlined as follows:

To calculate the net biomass production $\left(B_{n}\right)$ of a crop, an estimation of the gross biomass production $\left(B_{g}\right)$ and respiration loss $(R)$ is required:

$B_{n}=B_{g}-R$

The equation relating the rate of net biomass production $\left(b_{n}\right)$ to the rate of gross biomass production $\left(b_{g}\right)$ and the respiration rate $(r)$ is

$b_{n}=b_{g}-r$

The maximum rate of net biomass production $\left(b_{n m}\right)$ is reached when the crop fully covers the ground surface. The period of maximum net crop growth, i.e., the point in time when maximum net biomass increments occur, is indicated by the inflection point of the cumulative growth curve. When the first derivative of net biomass growth is plotted against time the resulting graph resembles a normal distribution curve. The model assumes that the average rate of net production $\left(b_{n a}\right)$ over the entire growth cycle is half the maximum growth rate, i.e., $b_{n a}=0.5 b_{n m}$. The net biomass production for a crop of $\mathrm{N}$ days $\left(B_{n}\right)$ is then

$B_{n}=0.5 b_{n m} \times N$

The maximum rate of gross biomass production $\left(b_{g m}\right)$ is related to the maximum net rate of $\mathrm{CO}_{2}$ exchange of leaves $\left(P_{m}\right)$ which is dependent on temperature, the photosynthesis pathway of the crop, and the level of atmospheric $\mathrm{CO}_{2}$ concentration.

For a standard crop, i.e., a crop in adaptability group I with $P_{m}=20 \mathrm{~kg} / \mathrm{ha} / \mathrm{hr}$ and a leaf area index of $\mathrm{LAI}=5$, the rate of gross biomass production $b_{g m}$ is calculated from equation

$b_{g m}=F \times b_{o}+(1-F) b_{c}$ 
where:

$F=$ the fraction of the daytime the sky is clouded,

$F=\left(A_{c}-0.5 R_{g}\right) /\left(0.8 A_{c}\right)$, where $A_{c}$ (or PAR) is the maximum active incoming short-wave radiation on clear days (de Wit 1965), and $R_{g}$ is the incoming shortwave radiation (both are measured in $\mathrm{cal} / \mathrm{cm}^{2} /$ day),

$b_{o}=$ gross dry mater production rate of a standard crop for a given location and time of the year on a completely overcast day (kg/ha/day) (de Wit 1965),

$b_{c}=$ gross dry mater production rate of a standard crop for a given location and time of the year on a perfectly clear day (kg/ha/day) (de Wit 1965).

When $P_{m}$ is greater than $20 \mathrm{~kg} / \mathrm{ha} / \mathrm{hr}, b_{\text {gm }}$ is given by equation

$b_{g m}=F\left(0.8+0.01 P_{m}\right) b_{o}+(1-F)\left(0.5+0.025 P_{m}\right) b_{c}$

When $P_{m}$ is less than $20 \mathrm{~kg} / \mathrm{ha} / \mathrm{hr}, \mathrm{b}_{\mathrm{gm}}$ is calculated according to

$b_{g m}=F\left(0.5+0.025 P_{m}\right) b_{o}+(1-F)\left(0.05 P_{m}\right) b_{c}$

To calculate the maximum rate of net biomass production $\left(b_{n m}\right)$, the maximum rate of gross biomass production $\left(b_{g m}\right)$ and the rate of respiration are required. Here, growth respiration is considered a linear function of the rate of gross biomass production (McCree 1974), and maintenance respiration a linear function of net biomass that has already been accumulated $\left(B_{m}\right)$. When the rate of gross biomass production is $b_{g m}$, the respiration rate $\left(r_{m}\right)$ is

$r_{m}=k b_{g m}+c B_{m}$

where $k$ and $c$ are the proportionality constants for growth respiration and maintenance respiration respectively, and $B_{m}$ is the net biomass accumulated at the time of maximum rate of net biomass production. For both legume and non-legume crops $k$ equals 0.28 . However, $c$ is temperature dependent and differs for the two crop groups. At $30^{\circ} \mathrm{C}$, factor $c_{30}$ for a legume crop equals 0.0283 and for a non-legume crop 0.0108 . The temperature dependence of $c_{t}$ for both crop groups is modelled with a quadratic function:

$c_{t}=c_{30}\left(0.0044+0.0019 T+0.0010 T^{2}\right)$.

It is assumed that the cumulative net biomass $B_{m}$ of the crop (i.e., biomass at the inflection point of the cumulative growth curve) equals half the net biomass that would be accumulated at the end of the crop's growth cycle. Therefore, we set $B_{m}=0.5 B_{n}$, and using (3), $B_{m}$ for a crop of $N$ days is determined according to

$B_{m}=0.25 b_{n m} \times N$

By combining the respiration equation with the equation for the rate of gross photosynthesis, the maximum rate of net biomass production $\left(b_{n m}\right)$ or the rate of net dry matter production at full cover for a crop of $N$ days becomes

$b_{n m}=0.72 b_{g m} /\left(1+0.25 c_{t} N\right)$

Finally, the net biomass production $\left(B_{n}\right)$ for a crop of $N$ days, where $0.5 b_{n m}$ is the seasonal average rate of net biomass production, can be derived as

$B_{n}=\left(0.36 b_{g m} \times L\right) /\left(1 / N+0.25 c_{t}\right)$

where:

$b_{g m}=$ maximum rate of gross biomass production at leaf area index (LAI) of 5,

$L=$ growth ratio, equal to the ratio of $b_{g m}$ at actual LAI to $b_{g m}$ at LAI of 5 ,

$N=$ length of normal growth cycle,

$c_{t}=$ maintenance respiration, dependent on both crop and temperature according to equation (8).

The potential yield $\left(Y_{p}\right)$ is estimated from net biomass $\left(B_{n}\right)$ using equation

$Y_{p}=H_{i} \times B_{n}$

where:

$H_{i}=$ harvest index, i.e., proportion of the net biomass of a crop that is economically useful.

Thus, climate and crop characteristics that apply in the computation of net biomass and yield are: (a) heat and radiation regime over the crop cycle, (b) crop adaptability group to determine applicable rate of photosynthesis $P_{m}$, (c) length of growth cycle (from emergence to physiological maturity), (d) length of yield formation period, (e) leaf area index at maximum growth rate, and (f) harvest index.

Biologically crops consume water for evapotranspiration (ET), and the rest of supplied water does not participate in the yield formation. In order to assess the productivity of ET, the following formula (13) is used:

$w_{p}=\frac{\text { Crop Yield }}{E T}$

The maps of the region were digitised and georeferenced using Er mapper software. Arcinfo software 
was used to change the coordinate system. For the meteorological stations, which were identified earlier within and adjacent areas, all the required parameters were estimated. For this purpose the guide lines reported by FAO (Allen et al. 1998) and other standard methods were used at regional scale. To calculate $B_{n}$ according to equation (1) the variables $F$ and $R_{g}$ based on radiation data should be calculated. Parameter $n$ is the measured actual radiation, measured period in hours per day. The values of this parameter are calculated from meteorological station data. At this stage, after evaluating the values of the parameter $n$, as the average monthly for each station, the relevant database was created. After linking the database to Arcview software and producing the station-point layer, a monthly grid map was prepared. Finally, after determining all the required information, $\mathrm{R}_{\mathrm{g}}$ layer of the region was created as monthly through interpolation with IDW method with 12 neighbourhoods with the power 2 . The next step, the data layer for the parameter $F$ was created and after extracting the parameters $b_{o}, b_{c}$ from relevant tables, $B_{n}$ layer was formed. Then, the appropriate correction factors should be applied for $b_{o}$ layer. In order to apply the correction factor to incorporate the crop variety and temperature, average monthly tempera- ture of meteorological stations in the area were called from Arcview software environment and the functions comprising map calculator, map Query and Reclassify operators were used to separate the different temperature zones, create relevant layers, and other correction factors, and the layer of spatial extent of potential yield (Yp) for winter wheat production in the region level were produced.

To determine the productivity of water use, in addition to the actual yield which is the numerator of equation (13), the denominator of the same equation which is actual evapotranspiration has to be determined. Thus the area was delineated into homogeneous regions using Theison method with Arcinfo software. Later, potential evapotranspiration was calculated using Cropwat software for each of these areas. These were converted into actual evapotranspiration using proposed FAO method (Allen et al. 1998). The maps of the actual evapotranspiration were prepared by the map calculator operator. These maps were overlapped with the spatial map of actual yield and the final map of spatial zones of water productivity of wheat crop in the Hamedan region was produced.

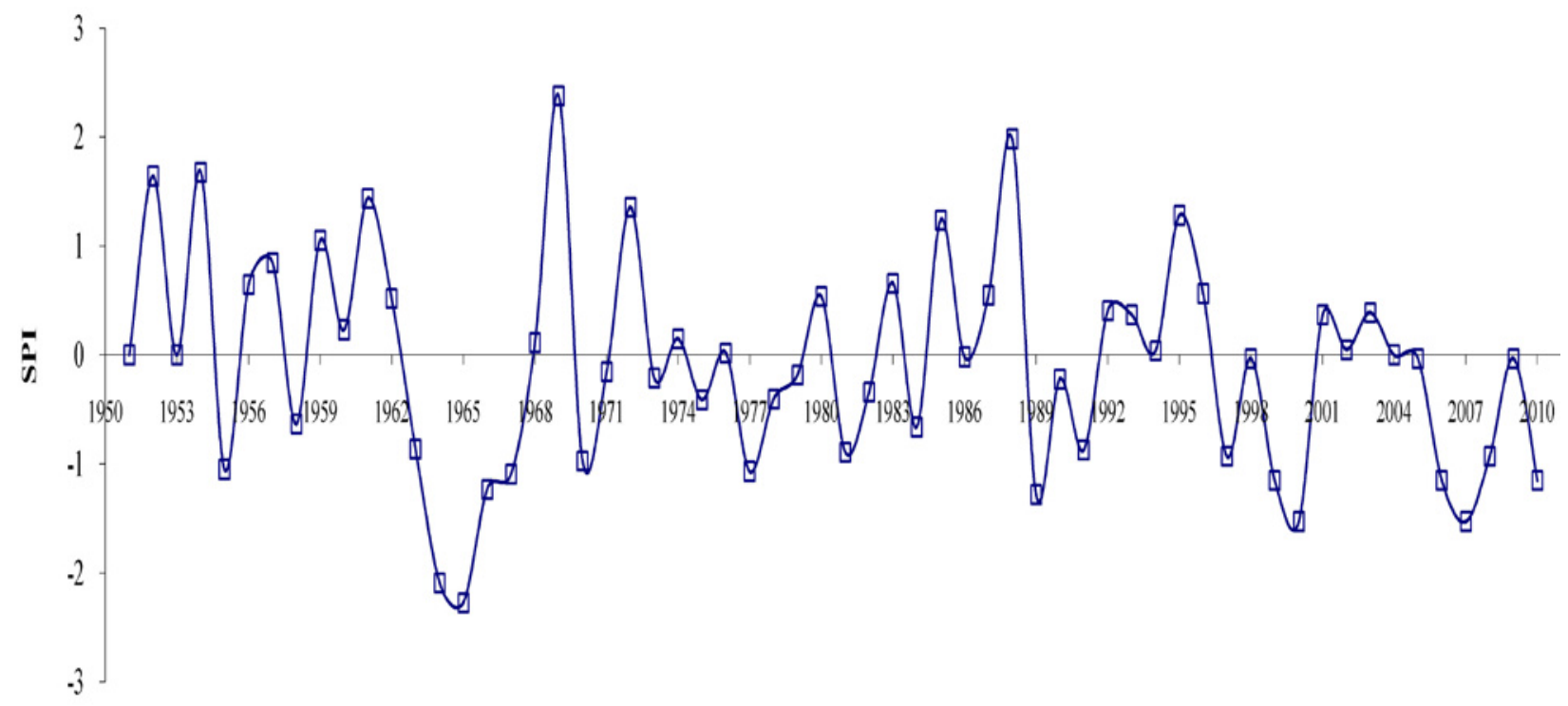

Year

Figure 1. A sample diagram of the temporal variation of SPI for 32 years span for Novejeh station 


\section{RESULTS AND DISCUSSION}

Figure 1 shows a sample diagram of the temporal variation of SPI for 32 years span for Novejeh station. Analysis of the calculated SPI for all the stations shows that, in general, in recent years, the region has experi- enced a drought state (C1) in 1999, and wet condition (C2) in 1992 and the normal state in 1989 (C3).

Figure 2 shows comparative statistics of water productivity in the area for the three conditions $\mathrm{C} 1, \mathrm{C} 2$, $\mathrm{C} 3$ and Figure 3 is the spatial distribution map of water productivity for drought condition.

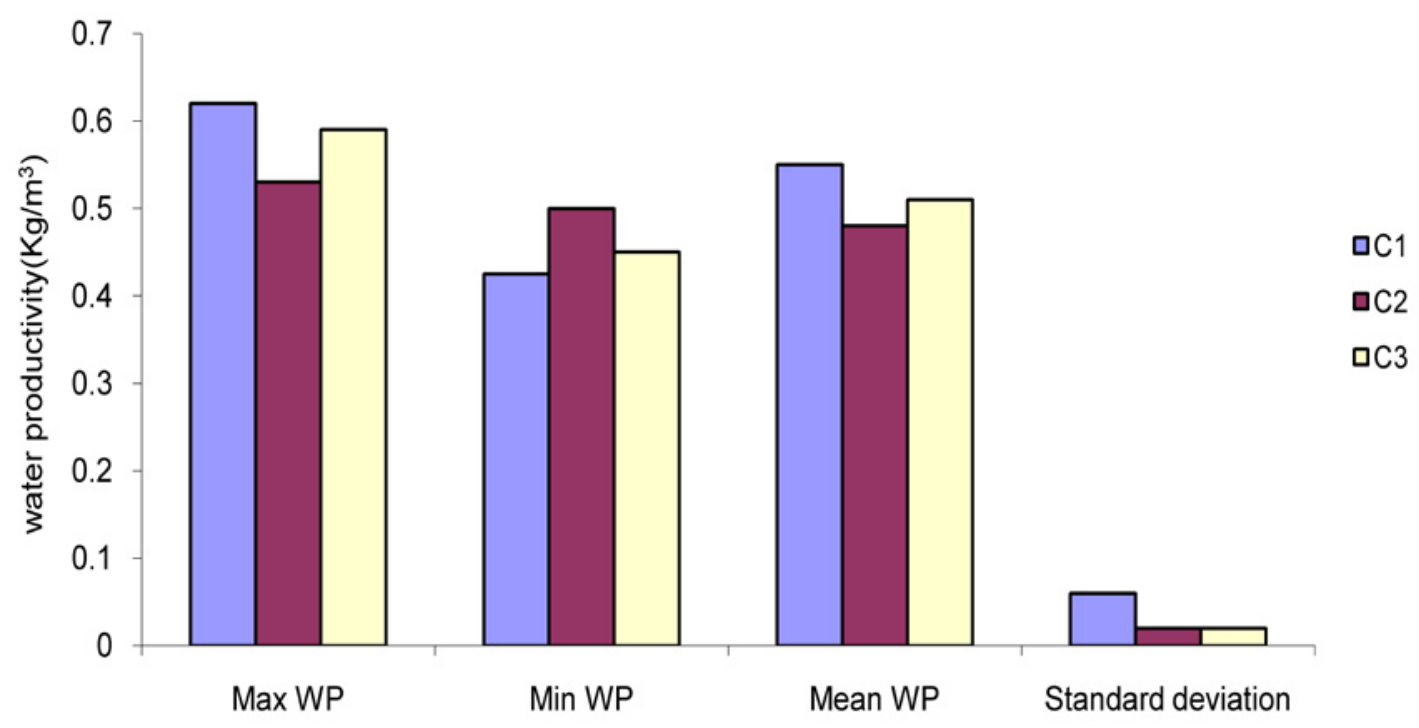

Figure 2. Comparative statistics of water productivity in the area for the three conditions $\mathrm{C} 1, \mathrm{C} 2, \mathrm{C} 3$

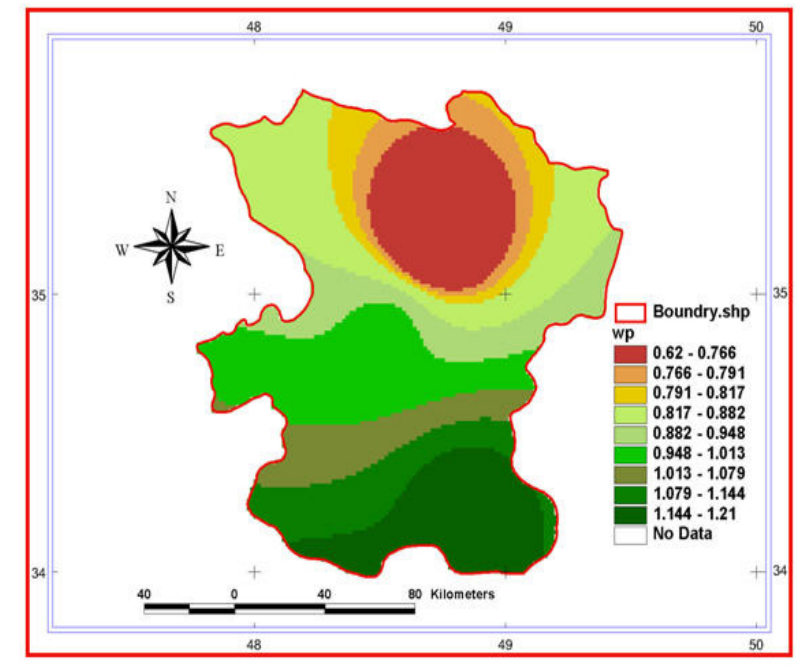

Figure 3. The spatial distribution map of water productivity for drought condition

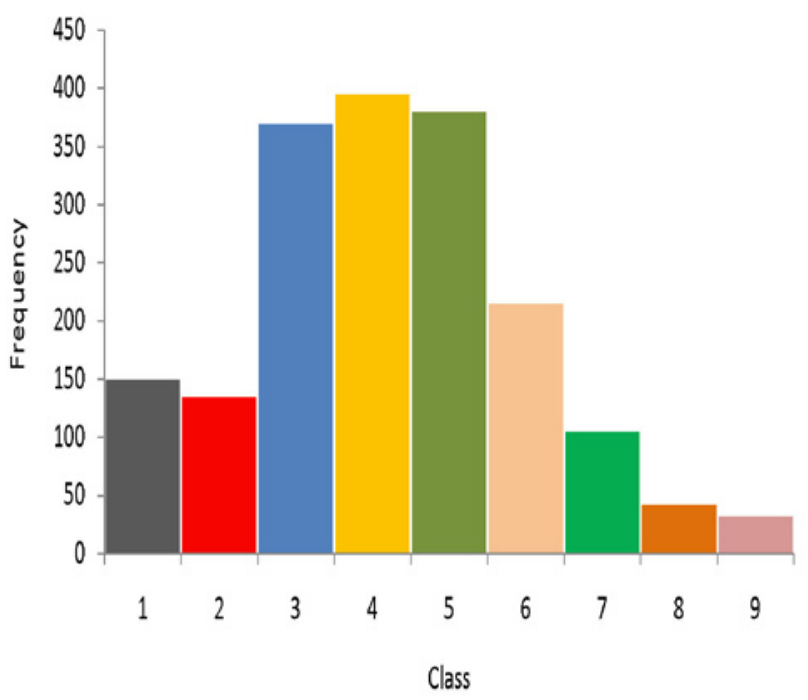

Figure 4. Frequency of water productivity in the area for drought condition 


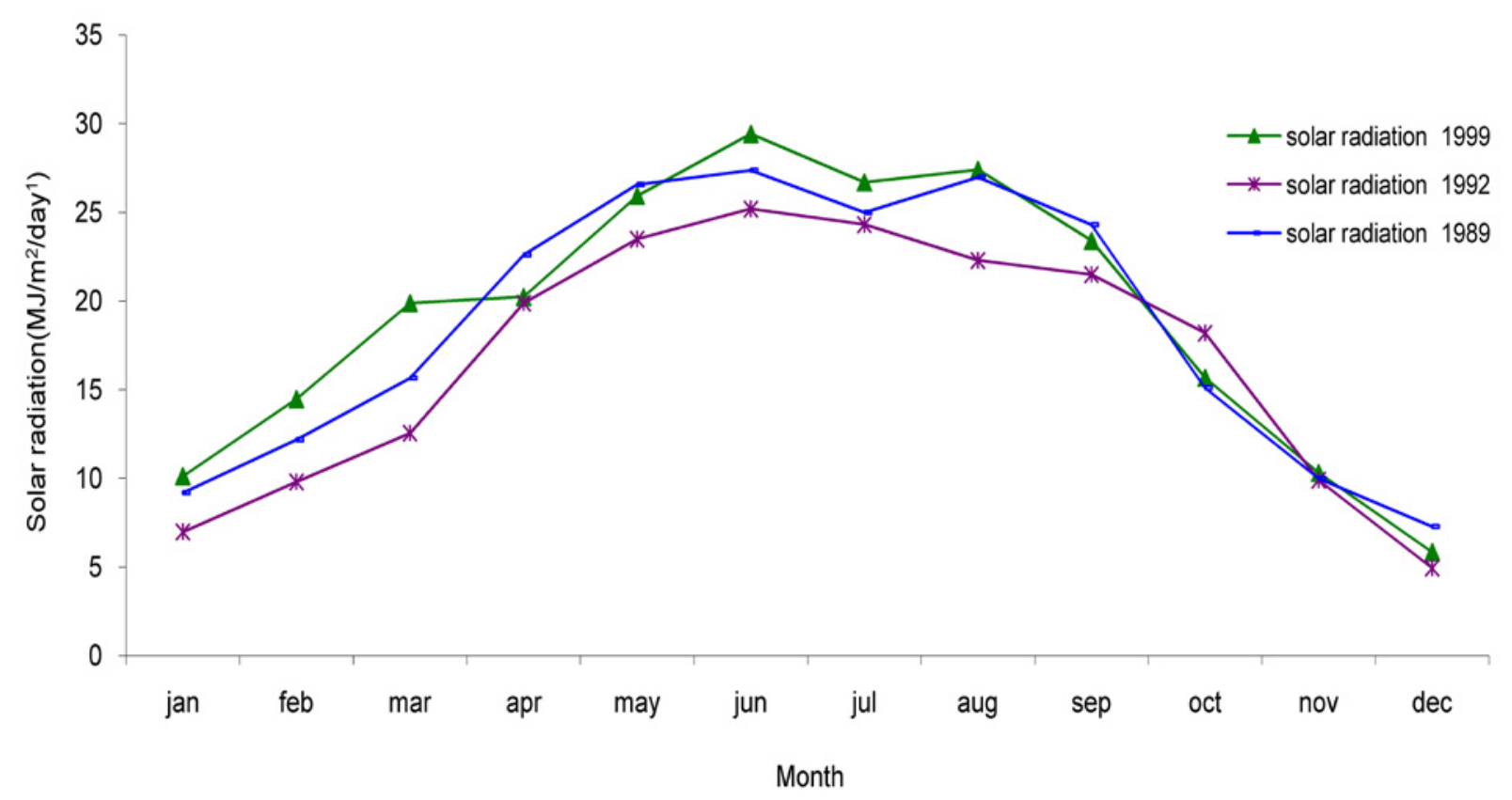

Figure 5. Variation of active SRAD received by the earth's surface in the three conditions

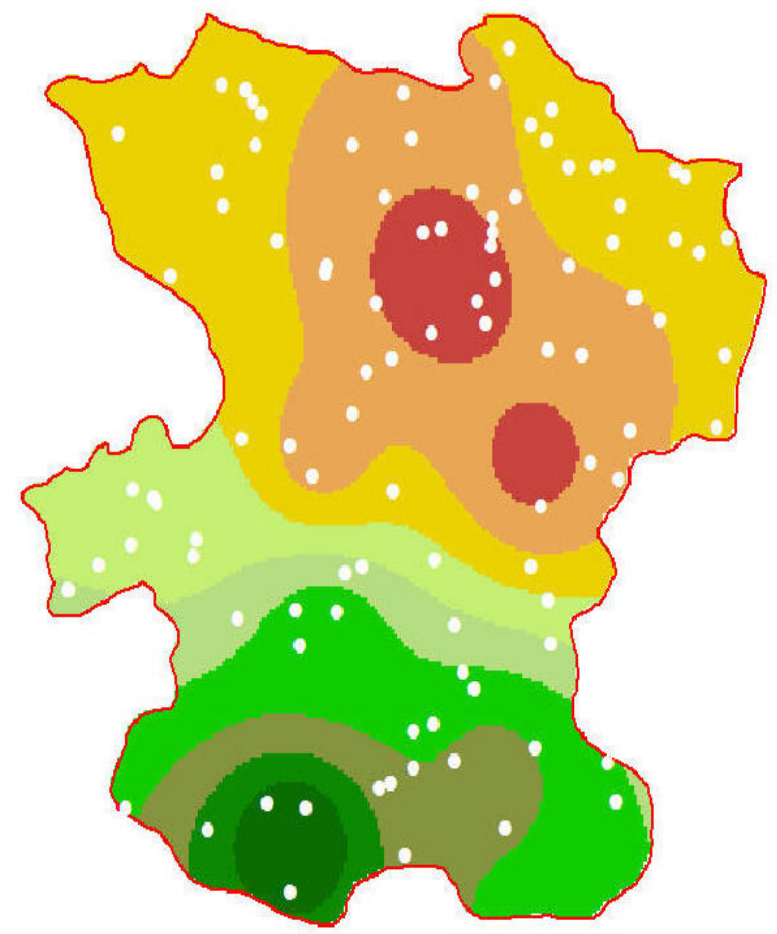

Water productivity

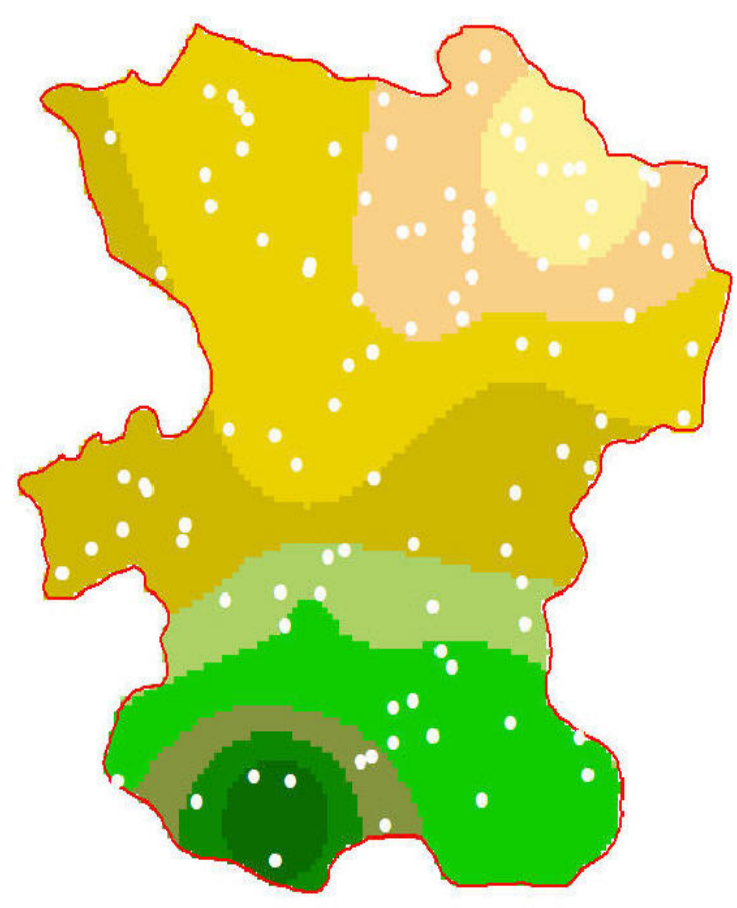

Solar radiation (SRAD) received by the earth's surface

Figure 6 . The extracted information from 100 randomly selected points on the two maps 


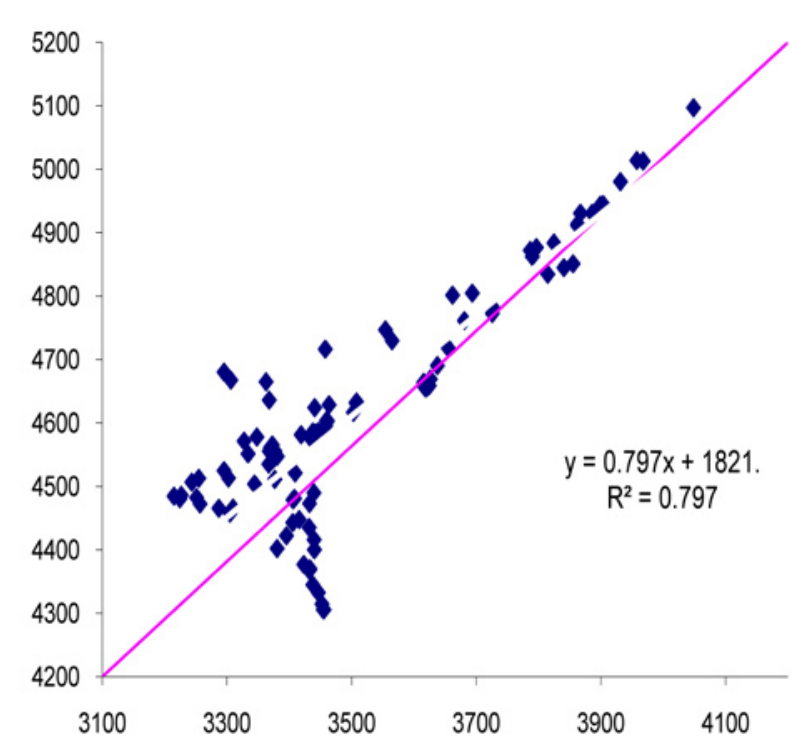

Figure 7. The regression between water productivity and SRAD maps

For the condition $\mathrm{C} 1$, the maximum water productivity (WP) is $0.67 \mathrm{~kg} / \mathrm{m}^{3}$ and South and South-east of the region has higher WP than the northern part. It should be noted that $\mathrm{C} 1$ condition has highest standard deviation in the region. Figure 4 shows that major part of the region has forth class water productivity ( 0.51 to 0.49). For $\mathrm{C} 2$ condition, the north-east and east regions have the maximum water productivity; $0.57 \mathrm{~kg} / \mathrm{m}^{3}$ and most of the regional area enjoys the forth class of water productivity $(0.47$ to 0.48$)$. Maximum water productivity $\left(0.61 \mathrm{~kg} / \mathrm{m}^{3}\right.$ for the $\mathrm{C} 3$ condition) is observed in extreme east and west of the region. These parts are placed in forth class of productivity ( 0.49 to 0.51$)$.

In dry conditions, like $\mathrm{C} 1$, average and maximum productivities are placed at a higher level than the other two conditions, contrary to what was expected in advance. But minimum WP in wetter condition is higher than dry condition. The reason is that in $\mathrm{C} 1$ the average solar radiation is higher than the other two conditions as it is observed in Figure 5. This has affected crop yield greatly. In other words, during the drought condition, maximum level of production is higher than in other conditions due to higher amount of active solar radiation (SRAD) received by the earth's surface in the growth period. This result was confirmed by other researchers that can be cited to Amor et al. (2002) .

Further, the analysis showed that spatial variation of WP is a function of spatial variations of solar ra- diation. The extracted information from 100 randomly selected points on the two maps (Figure 6) of spatial distribution of WP and spatial distribution of the active radiation as short wave reached towards the Earth's surface shows a good correlation $\left(\mathrm{R}^{2}=0.8\right)$. The regression line is shown in Figure 7.

Also Momeni et al. (2012) showed that there is an acceptable correlation between spatial distribution of WP and spatial distribution of the active radiation in their research, near the study area of this paper. They mentioned that with increasing the latitude, the amount of correlation coefficient will be increased.

\section{CONCLUSION}

The simultaneous investigation of the spatial and temporal dimensions of WP leads to a more effective analysis, comprehensive and in depth understanding of the condition of resources for planning and decision making. In addition, the results of such an analysis will provide more information to adopt suitable techniques for saving water in agriculture. It is clear that WP is sensitive to solar radiation and its spatial variations.

\section{REFERENCES}

AHMAD, M.D. - MASIH, I. - TURRAL, H. 2004. Diagnostic analysis of spatial and temporal variations in crop water productivity: A field scale analysis of the rice-wheat cropping system of Punjab, Pakistan. In Journal of Applied Irrigation Science, vol. 39, 2004, no. 1, pp. 43-63.

ALlEN, R.G. - PEREIRA, L.S. - RAES, D. - SMITH, M. 1998. Crop evapotranspiration: Guidelines for computing crop water requirements. Italy, Rome : Food and Agriculture Organization (FAO) press, 1998. 328 pp. ISBN 92-5-104219-5

AMOR, V.M. - ASHIM, D.G. - RAINER, L. 2002. Application of GIS and crop growth models in estimating water productivity. In Agricultural Water Management, vol. 54, 2002, no. 3, pp. 205-225.

BILLIB, M. - BARDOWICKS, K. - ARUMÍ, J. 2009. Integrated water resources management for sustainable irrigation at the basin scale. In Chilean Journal of Agricultural Research, vol. 69, pp. 69-80. DOI: 10.4067/ S0718-58392009000500007

EHSANI, M.- KHALEDI, H. 2003. Agriculture water productivity in order to supply water and food security. In 11th seminar of Iranian National committee on irrigation and drainage: proceeding from national conference. Iran : Tehran, 2001. ISBN 2251-6297, pp. 245-251.

HEINEMANN, A.B. - HOOGENBOOM, G. - DE FARIA, R.T. 2002. Determination of spatial water requirements at coun- 
ty and regional levels using crop models and GIS An example for the State of Parana, Brazil. In Agricultural Water Management, vol. 52, 2002, no. 3, pp. 177-196.

HUSSAIN, I. - TURRAL, H. - MOLDEN, D. - AHMAD, M.D. 2007. Measuring and enhancing the value of agricultural water in irrigated river basins. In Irrigation Science, vol. 25, 2007, no. 3, pp. 263-282. DOI: 10.1007/s00271-0070061-4

JAHANI, A. 2001. Water security and demand management. In 11th seminar of Iranian National committee on irrigation and drainage: proceeding from national conference. Iran :Tehran, 2001. ISBN 2251-6297, pp. 25-36.

KASSAM, A.H. 1977. Net biomass production and yield of crops. Present and Potential Land Use by Agro-ecological Zones Project. AGLS, Rome : FAO Press. 354 pp. ISBN 92-5-203890-6

KJINE, J.W. - BARKER, R. - MOLDEN, D. 2003. Water productivity in agriculture. In Limits and opportunities for improvement (eds) : proceeding from international conference. CABI : Wallingford, 2003. ISBN 9780851996691, pp. $145-162$.

McCREE, K.J. 1974. Equations for the rate of dark respiration of white clover and grain sorghum as functions of dry weight. Photosynthetic Rate and Temperature. In Crop Science, vol. 14, 1974, no. 4, p. 509-514. DOI: 10.2135/ cropsci1974.0011183X001400040005x

METEOROLOGICAL ORGANIZATION, available on internet: http://weather.ir/.

MOAYERI, M. - SIADAT, H. - PAZIRA, E.- ABBASI, F. - KAVEH, F. - OWEIS, T.Y. 2011. Assessment of maize water productivity in southern parts of the Karkheh river Basin, Iran. In World Applied Sciences Journal, vol. 13, 2011, no. 7, pp. 1586-1594.

MOLDEN, D.J. - SAKTHIVADIVEL, R. 1999. Water accounting to assess uses and productivity of water. In Water Resources Development, vol. 155, 1999, no. 1, pp. 55-71.

MOMENI, R. - BEHBAHANI, S.M.R. - AZADEGAN, B. 2011. Evaluation of increasing water productivity scenarios for rain-fed wheat by management analysis of CropSyst crop model in Karkheh basin. In Water and Irrigation Management, vol. 1, 2011, no. 1, pp. 29-40.

NAZARIFAR, M.H. - BANEJAD, H. 2007. Increasing of soil and water resources efficiency in drought conditions with agro ecological model- Case study Hamedan province. In 9 th seminar irrigation and evaporation control : proceeding from national conference. Iran : Kerman, 2007. ISBN 1028-7655, pp. 55-63.

OWEIS, T. - HACHUM, A. 2003. Improving water productivity in the dry areas of West Asia and North Africa. Water productivity in agriculture: Limits and opportunities for Improvement. ed. J.W. Kigne. Wallingford, UK : CABI, ISBN No.0851996698, pp. 183.

SHAH, S. - DALWADI, H.J. 2011. Critical appraisal of an irrigation command and water productivity based on satellite remote sensing. In International Journal of Water Resources and Environmental Engineering, vol. 3, 2011, no. 2, pp. 41-45.

SINGH, R. - JHORAR, R.K. - van DAM, J.C. - FEDDES, R.A. 2006. Distributed ecohydrological modeling to evaluate irrigation system performance in Sirsa district, India II: Impact of viable water management scenarios. In Journal of Hydrology, vol. 329, 2006, no. 2, pp. 714-723. DOI: $10.1016 /$ j.jhydrol.2006.03.016

de WIT, C.T. 1965. Photosynthesis of leaf canopies. Institute for biological and chemical research on field crops and herbage, Wageningen, Holland, Research Report No. 663.

YAZDANI, S. - M. HAGHSHENOO, B. 2008. Drought management and recommended solutions on how to deal with drought. In American Eurasian Journal of Agricultural and Environmental Science, vol. 2, 2008, no. 1, pp. 64-68. DOI: $10.1007 / \mathrm{s} 10333-011-0260-8$

ZAREABYANEH, H. - MAHBOUBI, A.A. - NEYSHABOURI, M.R. 2004. Evaluation of drought situation and its process in Hamedan region on the basis of drought statistical indexes. In Pajouhesh-va-Sazandegi, vol. 17, 2004, no. 3, pp. $2-7$.

Received: November, $3^{\text {th }}, 2011$ 